\section{Results of Treatment}

Roughly speaking, the results of treatment can be considered under two main headings, subjective and objective, although there is bound to be some overlapping.

Subjective.-Most patients stated that they felt less fearful and apprehensive and that the outside world appeared to be brighter and more real; there was an increase in selfconfidence, combined with a slight euphoria ; they felt more energetic and active.

Objective.-Behaviour-patterns became less withdrawn, and the patients seemed to be less apathetic and scared, and better adjusted to their environment. Their general attitude became manifestly more sthenic and virile. Those patients who had shown an undifferentiated or homosexual orientation began to develop heterosexual interests, although there were no observable changes from the anatomical point of view. Two patients became more accessible so far as analytical psychotherapy and rehabilitation were concerned.

Cases 2 and 8 became more deluded and paranoid, and so aggressive that treatment had to be discontinued.

\section{Conclusions}

It is clear that dehydroisoandrosterone can alter mental states even in the case of schizophrenic illness of long standing. The chief effect of the drug would seem to be to increase self-confidence and to induce a slight euphoria. In the case of two patients, in whom delusion-formation was a prominent symptom, increased aggressiveness and nervous tension occurred in the course of treatment.

Further work will be needed to show whether these changes are in any way related aetiologically to the reestablishment of the normal spectrum of 17-ketosteroid excretion, either by substitution therapy as in Cases 2 to 5 or by suppression of an abnormality, as might explain the result in Case 1. It is perhaps noteworthy that all the patients mentioned in this paper were constitutionally immature, and more or less conformed to Kretschmer's description of pubertal retardation. In some cases the symptomatology resembled that of prolonged unresolved pubertal crises-again in Kretschmer's sense-rather than a true process-schizophrenia. These preliminary results suggest the possibility that the beta fraction of the 17-ketosteroids represents the metabolites of substances which may be concerned with the development of "self-confidence" in adolescence or early adult life, in a way somewhat similar to the adrenal stimulation of A.C.T.H. in raising resistance to general stress (Selye, 1950).

In the case of a drug with such positive results it is necessary to be very cautious in the matter of dosage and to vary the dose from patient to patient in accordance with constant psychiatric observation. Special prudence is demanded when aggression is present in the symptom-picture.

The results of treatment in this small group suggested that dehydroisoandrosterone might be of value in the case of constitutionally inadequate and anxious juveniles, especially those with a tendency to schizoid psychopathy. Further investigations on these lines at St. Ebba's Hospital are reported by Sands and Chamberlain (1952).

We should like to acknowledge our indebtedness to Dr. E. F. Scowen, Dr. H. Crichton-Miller, and Dr. R. E. Hemphill, to all those who rendered assistance in this preliminary communication, and especially to Organon Laboratories for supplies of dehydroisoandrosterone.

REFERENCES

Sands, D. E., and Chamberlain, G. H. A. (1952). Brittsh Medical Journal, 2, 66.

\section{TREATMENT OF INADEQUATE PERSONALITY IN JUVENILES BY DEHYDROISOANDROSTERONE}

\section{PRELIMINARY REPORT}

BY

\author{
D. E. SANDS, F.R.C.P.Ed., D.P.M. \\ AND
}

\section{G. H. A. CHAMBERLAIN, M.D., M.R.C.P.I., D.P.M. (From St. Ebba's Hospital, Epsom)}

Thirteen of the juvenile cases in the special unit at St. Ebba's Hospital for those aged 12 to 17 years have been distinguished by constitutional and emotional immaturity. Some were also intellectually dull. As a group they were inadequate, timid individuals, lacking confidence, and several were distinctly effeminate in attitude. They were physically small, looked younger than their years, and in two of the thirteen the genitalia were undersized and the testes incompletely descended. Eight were predominantly schizoid, three mainly anxious, one was a case of hysteria, and one an inadequate psychopath. In fact, such patients appeared to be the potential chronic schizophrenics or inadequate psychopathic personalities of early adult life. In view of the changes in mental state produced by dehydroisoandrosterone in a small group of young male adults of similar mental habitus, as reported by Strauss et al. (1952), it was thought possible that the drug might be worth a trial in this younger group, so lacking in development of the normal male confidence and assertiveness of youth.

By contrast, trial dosage of the drug was also given to four juveniles known to have aggressive trends. The average age of both groups was 15 years. Total 17ketosteroid estimations were done in all but one case, though patients were selected on essentially clinical grounds. All patients had undergone the usual routine investigations and psychotherapeutic interviews for a month, and often more, before they received dehydroisoandrosterone.

The drug was given at first by injection only, the dose ranging from $0.5 \mathrm{ml}$. bi-weekly to $2 \mathrm{ml}$. daily-that is, $10-40 \mathrm{mg}$. No difference in effect was -noticed when a change was made to oral administration in tablet form.

Specimen case histories are given below, but the general reaction to the drug was as follows. These patients were either schizoid, anxious, or inadequately psychopathic; and were characterized by feelings of inferiority, vagueness, timidity, apathy, and lack of social confidence. They mixed uneasily with others and at times were homosexual or effeminate. On giving dehydroisoandrosterone no immediate changes were noted, but after a period which varied from four days to four weeks, according to individual differences and the size of the dose, the following type of response was seen to a greater or lesser degree in the whole selected group of thirteen cases. First, there was an increase in activity, showing as improved performance in school or occupational department and ability to discuss their feelings and future aims. Confidence increased, and at the same time timidity and vagueness diminished. Relations with their fellows became more normal, and in some who had been prone to homo- 
sexuality the attitude became obviously heterosexual. There was little sign of any definite action on mood per se, but arising out of this swing towards better adjustment there was obvious contentment, with disappearance of depression. Weight was gained or maintained in all cases, but otherwise there was no noticeable physical change or maturation.

These changes are illustrated individually by the following four cases : two mainly schizoid, one chiefly anxious, and one inadequately psychopathic.

\section{Case 1}

A boy aged 15 was described as having been reserved, not mixing with other boys or fond of sports, but seclusive in his habits and given to excessive day-dreaming. He was inhibited and kept his thoughts to himself. In the past four years he had truanted, lost six jobs in the last few months, pilfered, lied, and become quite uncontrolled. His parents were divorced, and he had been deprived of parental care. After admission he appeared retarded, apathetic, and depressed. His intelligence was low average, and the E.E.G. doubtfully normal. The Rorschach test summarized him as immature, without affective response, and suggested early schizophrenia. In a few weeks he lost his depression, but continued to be emotionally dull and indifferent, though well enough to be tried at educational classes outside hospital. After eight weeks he gave up his classes and occupied himself with gardening in the grounds. On the whole he was more responsive and sociable, and was offered a suitable paid job locally. He soon again became more solitary and detached, and was found wandering outside hospital in a depressed, dazed state. When he had settled again he started routine work in the laboratory under supervision. He said that he liked strict supervision and feared to take any responsibility or initiative himself.

$\mathrm{He}$ was started on $20 \mathrm{mg}$. of dehydroisoandrosterone on alternate days, rising to $20 \mathrm{mg}$. daily. Three to four weeks later he was seen to be more energetic, was working better, was more cheerful, and was mixing in games. His whole attitude and approach improved. After three and a half months on the drug he was able to discontinue it and to take up a factory job, which he has held for seven weeks without relapse. Though treated psychotherapeutically, the addition of the drug seems to be giving him the necessary confidence to make decisions and to hold a settled course in a contented way.

\section{Case 2}

A boy aged 14 was always regarded as a quiet detached youngster, shrinking from personal contacts, solitary, and effeminate by nature. During the past year he had been repeatedly truanting, though extremely self-conscious and oversensitive to criticism. He became preoccupied with the "psychology of religion," felt that he was "different," showed little emotional response, and was much absorbed with his own thought processes.

On admission he was vague and detached and gave long rambling explanations of his religious ruminations. He said that he felt empty, and at times laughed incongruously. He mixed with few other boys ; and his odd manner persisted. A month after admission he was started on a course of dehydroisoandrosterone, $1 \mathrm{ml}$. (20 mg.) intramuscularly on alternate days for nine weeks. After ten days he showed a considerable change, being more naturally self-assertive in manner and playing more readily with other boys; though he still discussed religion in a vague way, he was much more in touch with events. He had shown some homosexual trends, but these also disappeared during his treatment. Eventually he declared that he had lost his preoccupation with religious fantasy; and it was obvious that his social adjustment had greatly improved. In this condition he was discharged home.

\section{Case 3}

A boy aged 15 had been regarded as having a solitary type of make-up, prone to worry, to be preoccupied with the future, and to day-dream. He was much disturbed five months before admission, when his dog was destroyed; and after a subsequent attack of influenza became moody, disinterested, and depressed, with much irritability. He took six aspirin tablets and said that life was not worth living. He also attempted to suffocate himself with pillows. Physically he was undersized for his years, and appeared immature, with under-development of genitalia and pubic hair. To some extent he seemed to identify himself with his mother and her proneness to worry and over-anxiety. At first he was depressed and lacrimose, and had a number of physical symptoms. He showed improvement from the acute depressive reaction, but then appeared more frankly overanxious and oversensitive. He felt that he was a failure and worried over the opinions of others, with guilt over masturbation and feelings of sexual inferiority.

He was treated mainly by psychotherapy, but little real progress was made until he was given dehydroisoandrosterone, $10 \mathrm{mg}$. twice a week. It was later felt that this dose was rather inadequate, since it was nearly eight weeks before he began to improve, to become more naturally aggressive, and to co-operate much better in psychotherapy and the discussion of his problems. Though more progress might have been made at first with a larger dose, it was certainly enough for him latterly, since he changed so much that on one or two occasions it was necessary to reprimand him for bullying other boys. After eleven weeks he was able to return home to his parents, and appeared to have recovered.

\section{Case 4}

This patient, aged 16 , had been generally regarded as an immature sensitive youngster, with feelings of inferiority. $\mathrm{He}$ avoided boyish activities and often impressed others as being effeminate - enjoying knitting, sewing, and dressing dolls. He had few interests and in general was shy and reserved. Eighteen months before admission he began absconding from work and home, and stole a bicycle, subsequently returning it to the police.

On admission he appeared to be emotionally immature, though physically well developed. He was dull and childish, and handicapped by an over-indulgent mother and an indifferent father. Much of his thought was of a grandiose, wish-fulfilling type. He feared the onset of adulthood and its responsibilities. He wanted a nursing job, looking after children and babies. His mother's attitude had not helped him, since, while condemning him for childish sex explorations, she refused to discuss these matters with him in any enlightened way. He expressed dislike of the physical aspects of marriage. He was given $10 \mathrm{mg}$. of dehydroisoandrosterone on alternate days for seven weeks; and after three weeks showed much improvement, being more lively, taking a leading rather than an inadequate part with other patients, losing his effeminate habits, and mixing normally with the opposite sex. As his social improvement increased he gained further confidence. He was discharged, much improved, after eight weeks, returning to his parents, having secured himself a job.

\section{Other Cases}

By contrast the drug was also given to four juvenile patients of a different type-three of schizoid and schizophrenic types and one psychopathic personality. All these patients showed aggressive features in their history, as opposed to the predominantly inadequate characteristics of the first group. On the same dosage as the latter, the aggressive psychopath of 18 years had to stop treatment after four weeks on account of the development of outbursts of rage and destructive behaviour, which settled a week after the drug was discontinued. During the past year he has never displayed aggression so intensively again.

A patient of schizoid personality with a history of aggression and attacks of temper became more alert and spontaneous after two to three weeks on the drug, but after six and a half weeks showed an increase of tension and aggression, attacked other patients, and had to be moved 
temporarily to an acute ward. Another aggressive young schizophrenic showed an increase in impulsive, mischievous, and aggressive conduct two weeks after starting the drug. This phase continued for three to four weeks, though the drug was stopped four days after the change began. A paranoid juvenile schizophrenic case, not particularly immature physically or emotionally, became more acute with increased tension, attempted to smash a window, and required heavy sedation to relieve the situation.

\section{Discussion}

The most significant effect of dehydroisoandrosterone is that it modified the behaviour of selected juveniles, and this effect was consistent in trend and form. Those who were socially and emotionally inadequate gained by becoming more normally confident, alert, and able to mix with their fellows. Those liable to be over-aggressive in mental make-up were made worse and appeared overstimulated by the drug. In both types the effect was temporary, since the "inadequate" patients, with two exceptions, tended to relapse, and the aggressive settled down to their usual state when the drug was discontinued. The presence of schizoid, anxious, or depressed features seemed to be of secondary importance in the selection of patients for this treatment, provided the inadequacy was present, as just described. Pending further investigation it can be said that dehydroisoandrosterone acts as a form of replacement therapy, and that effective treatment is likely to be prolonged and the dosage varied according to individual needs. The usual range lies between 5 and $30 \mathrm{mg}$. or more, whether by injection or in tablet form.

Total 17-ketosteroid estimations, with two tests per patient, were performed in all cases. Irrespective of clinical type, half the patients proved to be within the average range for their age group and half were found to have low ketosteroid output in the urine. Estimation of total 17-ketosteroids was of little value in the selection of patients for treatment, which was done entirely on clinical grounds, as described. There is some indication, as noted in the paper of Strauss et al., that selection may be possible through the fractional estimation of the 17-ketosteroid group. No alteration in primary or secondary sexual characteristics was noted. Dosage should be related to individual needs, not only for adequate treatment but to avoid complications.

The electroencephalogram was recorded in all but one case. The number of normal results exceeded the usual proportion for this age range in those admitted to the juvenile unit. No significant deductions could be made in this small series.

All cases had failed to respond to other measures before dehydroisoandrosterone was begun. In this group of thirteen inadequate cases two recovered during treatment, five were much improved, three improved, and three others showed only temporary gain. None were worse, as happened temporarily in the four aggressive cases. Eight patients have been discharged.

Follow-up for the maximum of a year after the drug was stopped showed that of the thirteen patients only three have continued in their recovered and improved state, while the rest have suffered varying degres of relapse. It is obvious that in many cases the treatment will require to be prolonged over months to be of any lasting value.

While this treatment may replace certain factors lacking for normal constitutional endowment, it is not a substitute for proper psychotherapeutic investigation, though progress in psychotherapy can be accelerated through improved rapport. Furthermore. the gain in self-confidence enables many of these cases to take up the ordinary social and occupational pursuits of adolescence.

We are most grateful to Dr. W. W. Kay and to Mr. L. D. G. Hamilton, of the Mental Hospitals Group Laboratory, West Park Hospital, for their assistance and advice on 17-ketosteroid estimations; also to Organon Laboratories for supplies of dehydroisoandrosterone.

REFERENCE

Strauss, E. B., Sands, D. E., Robinson, A. M., Tindall, W. J., and

W. A. H. (1952). British Medical Journal. 2, 64

\section{THE TREATMENT OF SJÖGREN'S SYNDROME WITH A.C.T.H.}

BY

EWAN F. B. CADMAN, M.D., M.R.C.P., D.C.H.

AND

A. JOHN ROBERTSON, M.D., M.R.C.P.

(From the Department of Medicine, University of Liverpool)

In 1933 Sjögren described the ocular component of the condition which now bears his name, and which is becoming more widely recognized. It occurs mainly in middle-aged women, and consists of dry mucous membranes, parotid gland enlargement, and arthritis, though the syndrome is often incomplete. Kerato-conjunctivitis - sicca is an essential part of the disease, and rhinitis sicca, xerostomia, pharyngitis sicca, and laryngitis sicca may occur. The lacrimal glands are involved but rarely palpable. In addition, an increased erythrocyte sedimentation rate, hypochromic anaemia, low blood sugar, achlorhydria, and alopecia have also been described (Weber, 1945).

A.C.T.H. has been used by us to treat two cases, and these are discussed below.

\section{Case 1}

A 60-year-old housewife was first seen in June, 1951. complaining of a dry mouth. Apart from some rheumatoid arthritis which began after the menopause at the age of 51 , she had been perfectly well until March, 1948, when she had "influenza." She was kept in bed for a week with generalized aches and pains and loss of appetite, and immediately afterwards she noticed a wide variety of symptoms. Her sense of taste and smell disappeared, and her eyes became sticky and dry. Her mouth became very dry, making many foods difficult to chew, and she noticed that she was getting swellings near the angles of her jaw. These changed the shape of her face, seemed to vary a little in size, and were sometimes painful. Cracks developed at the corners of her mouth in June, 1950, but otherwise her symptoms had continued unchanged for about three years.

On examination each parotid gland was much enlarged but not tender, and she had severe rheumatoid arthritis with ulnar deviation in her hands. Her tongue was smooth, dry, and magenta-coloured, and her mouth was dry. There was an angular cheilosis, and she had kerato-conjunctivitis sicca. In addition there was a greatly enlarged liver and spleen, each being about five fingerbreadths below the costal margin.

A clinical diagnosis of Sjögren's syndrome was made, but the various laboratory investigations failed to reveal the underlying pathology or to account for the hepatic and splenic enlargements. Her plasma proteins were abnormal, in that she had a total of $9.2 \mathrm{~g}$. per $100 \mathrm{ml}$., with albumin 3.55 g., globulin 5.65 g., and $A / G$ ratio $0.63 / 1$ by Howe's technique. Her gamma-globulin was $4 \mathrm{~g}$. per $100 \mathrm{ml}$. (Cohn's technique), and no doubt this accounted for the abnormal flocculation tests, which were compatible with hepato-cellular damage. A liver puncture showed no abnormality of the liver gells, but one portal tract was filled with lymphocytes. The haemoglobin was $11 \mathrm{~g}$. per $100 \mathrm{ml}$., with $3,700,000$ red cells per c.mm. There was a neutropenia with a total of 2,000 white cells per c.mm. (280 polymorphs, 1,100 lymphocytes, 560 monocytes, 20 eosinophils, and 40 basophils). The sternal marrow was within normal limits, as were the blood-calcium, bloodphosphate, blood-sugar, urine, bleeding-time, clotting-time, and prothrombin-time estimations. The fractional test meal showed a low acid curve, and $x$-ray films of the hands and 